\title{
How Pre-service Teachers Internalize the Link between Research \\ Literacy and Pedagogy
}

\begin{abstract}
Enabling pre-service teachers to develop a critical view of their practice and to acquire the higher order inquiry skills necessary for pedagogic research has been and continues to be a challenge. The present study presents a unique intervention in the training of pre-service teachers in research skills (research literacy) using a Problem Based Learning (PBL) approach. The intervention is implemented in two different Learning Communities (LC), one online and the other blended. Both immediate and long-term effects of PBL are investigated as are the effects of social and direct scaffolding within the LCs.

The study focuses on transmitting the following Research Literacy (RL) skills: identifying and defining a problem, formulating a research question, and designing a research method. The findings indicate an immediate effect upon all $R L$ skills in both LCs. The long-term effect appears only in the online LC and only for two RL skills: identifying and defining problems. Additionally, there is greater use of social scaffolding in formulating and designing a research study in the online LC than in the blended learning community. Those findings are then interpreted in terms of retention capacity and scaffolding in blended and online LCs.
\end{abstract}




\section{Introduction}

There is a growing need to train pre-service teachers to incorporate research and inquiry skills into their pedagogic practice and to start such training from the earliest stages of teacher training. This requires educators to emphasize the ability to identify and reflect on pedagogical problems and to formulate appropriate research questions in order to investigate them. With these skills, pre-service teachers will be equipped to design research and to gather, interpret, and use data about student learning at the practical level (HampdenThompson \& Sundaram, 2013).

Problem Based Learning (PBL) facilitates pre-service teachers' internalization of the link between research skills and pedagogy. It is a solution to the longstanding challenge of translating the theoretical aspects of research literacy $(\mathrm{RL})$ into practical pedagogical skill (Willcoxson, Manning, Johnston, \& Gething, 2011). The present study applies the PBL model in both online and blended Learning Communities.

\subsection{PBL and Research Literacy}

The PBL approach is based on a constructivist outlook including two principles essential to the internalization of $\mathrm{RL}$ (Creamer, Ghoston, Drape, Ruff, \& Mukuni, 2012): the use of authentic problems and collaborative learning. PBL exposes students to actual educational dilemmas so they can experience the education-based "troubleshooting" which will be expected of them as professionals. Collaborative learning scaffolds students' ability to design appropriate processes and solutions for educational dilemmas through structured cooperative discussions (Wright, 2011). A PBL approach to RL 
enhances learners' abilities to identify problems in their practice, to formulate assumptions about the factors that produce the problem, and to activate $R \mathrm{~L}$ patterns of thinking in order to develop appropriate educational interventions (Hampden-Thompson \& Sundaram, 2013). Very few studies have investigated PBL in the instruction of Research Literacy (Earley, 2014). The present investigation extends current knowledge about the efficacy of PBL in developing research skills among pre-service teachers.

\subsection{PBL and learning communities}

The collaborative learning which constitutes $\mathrm{PBL}$ is carried out in a community of learners. PBL was initially conducted in classroom environments; however, the latest studies (Baturay \& Bay, 2010; Donnelly, 2010) indicate its successful adaptation to online learning communities. In this format collaborative learning heightens motivation and increases the feeling of connection to other learners.

Building on the motivation and social connection generated by $\mathrm{PBL}$, the current study attempts to determine the extent to which PBL strengthens the link between $R L$ and pedagogy both in blended and in online learning communities. The scaffolding that facilitates the ability of student teachers to assimilate the connection between $R L$ and pedagogy (Willcoxson et al., 2011; Barber, King, \& Buchanan, 2015) is also investigated as is the efficacy of integrating $\mathrm{PBL}$ into $\mathrm{RL}$ in blended and face-to-face learning communities (Barber et al., 2015; Donnelly, 2010; Bettaz et al., 2016).

The first goal of this study is to evaluate the influence of PBL on student awareness of the link between $R \mathrm{~L}$ and pedagogical practice. Student 
performance in both online and blended learning communities is compared to determine which learning environment increases the proficiency in assimilating this link. The scaffolding process employed in online forums in the two different learning communities is also analyzed as a support for reflective discussion and meaning making.

\section{Method}

\subsection{Participants and Research Design}

The research subjects were 62 second-year pre-service teachers who were enrolled in a 12-week course (one academic semester) in RL in Education consisting of 28 hours.

There were two differently formatted courses, one online, referred to as online learning community (OLC) and the other a blended environment, referred to as blended learning community (BLC). Each course had two sections. The demographic parameters (age, study period) of the two groups were equivalent (Table 1). All four sections were engaged in a similar learning program based upon the same course content, learning materials, exercises and tasks and taught by the same instructor.

A major requirement of all four courses was participation in online discussion forums that consisted of PBL experiences. Each forum focused on a different $R L$ skill about which participants were required to reflect and discuss. The four reflective online forums served as four-week discussion platforms designed to allow students to provide their own examples of research problems that they had recently faced, and with their classmates' help generate appropriate research questions, educational interventions, measures, and processes. The 
members of the BLC participated in lectures and discussions in a F2F environment and also took part in the online forums. Members of the OLC studied on their own assisted by online learning materials and then took part in identical online forums. In the first forum, pre-service teachers cooperatively defined the term "research problem." In the second, they identified a particular research problem that they face in the field. In the third forum, they discussed and then formulated an appropriate research question. And in the fourth and last forum, they collaboratively designed a procedure that was suitable for investigating their research question (Tuckman \& Harper, 2012). These four PBL forums formed the basis for evaluation of the direct and social scaffolding.

\subsection{Measures}

The mixed research method of this study included a Research Literacy Inventory $(R L I)$ which consisted of student self-reports, a Research Literacy Task (RLT) which reflected actual academic performance, and an analysis of the virtual forums of both groups. Figure 1 shows a summary of the research procedure and the issues examined during the course.

\subsubsection{Research Literacy Inventory (RLI)}

The RLI (Shank \& Brown, 2013), customized to the needs of the present study contains participants' self-assessment on 18 items using a five-point Likert-scale (alfa). Administered before and after the intervention, it analyzes the immediate effect of PBL with a one-way MANOVA and a repeated measures design.

\subsubsection{Research Literacy Task (RLT)}


An open-ended learning task based upon analysis of an empirical article by Hacohen \& Ronen (2011) was given to students one month after the intervention to assess the long-term effect of PBL. The pre-service teachers were required to: (1) analyze the article, (2) define the problem described

therein, (3) identify a similar problem in their own pedagogical practice, (4) formulate an appropriate research question, and (5) design an appropriate research method, explaining its value. This task, evaluating the students' ability in all four RL skills was based on the PBL activities as well on as the pre-service teachers' personal experience in the field. The RLT was assessed by the following scoring scheme (Figure 2).

For each item of this task, students received a score from 1 to 4 points. Items exhibiting a strong link between $\mathrm{RL}$ and pedagogy earned a grade of either 4 (conceptual and procedural arguments) or 3 (procedural arguments). Answers including $\mathrm{RL}$ only earned a grade of either 2 (conceptual understanding) or 1 (procedural understanding). The analysis was carried out using a one-way MANOVA and Cohen effects (post-testing occasion X 2 groups).

\subsubsection{Reflective discussion protocols}

PBL processes were evaluated according to the reflective discussion protocols gathered in the virtual forums in each online or blended LC. The first forum focused on identifying a research problem existing in the field and discussing it. The second forum focused on defining a research problem in the appropriate terms. The third forum focused on formulating research questions. The fourth forum focused on designing appropriate research methods. The protocols of all forums were axially coded by separating 
contributions to the forum into direct scaffolding (the number of new topics which were initiated by each participant) and social scaffolding (the frequency of replies to classmates' topics).

Direct scaffolding indicates student ability to create reflective discussions. The success of these initiatives was assessed by the frequency of replies to each new topic initiated in the forum. Social scaffolding assesses student willingness to take part in reflective discussions initiated by peers (scored by the number of responses and reactions during conversations by each participant).

\section{Results}

\subsection{Immediate effect of PBL on RL}

The first research question seeks to determine whether there is an immediate effect size in RL awareness in the different groups as measured by selfreporting. First, a MANOVA differential measures on the RLI (pre- and postcourse) X 2 groups (OLC, BLC) was performed. Then an ANOVA repeated measures was performed on each component of RL: defining, identifying, formulating, and designing. Table 2 presents the means and standard deviations for the RLI by testing occasion (pre- and post-test) and type of learning community (OLC and BLC).

The differential effects of PBL on $R L$ in the two groups (OLC, BLC) were compared. The MANOVA for the pre- and post- test indicate that before the PBL-based intervention there were no significant differences in $R L$ in the two groups: $F(4,60)=0.36, p>0.5$, partial $\eta 2=0.024$. The post-test as well does 
not show significant differences in $R L$ between the groups: $F(4,60)=0.64$, $p$ $<0.5$, partial $\eta 2=0.041$.

No significant differences emerged for individual RL skills identify, define, formulate and design: $F(1,63)=0.17, \boldsymbol{p}>.05 ; \mathrm{F}(1,63)=0.15, \boldsymbol{p}>.05$; $\mathrm{F}(1,63)=0.06, \boldsymbol{p}>.05 ; \mathrm{F}(1,63)=0.24, \boldsymbol{p}>.05$, respectively. However, repeated measures indicate a significant increase in $R L$ awareness for each component for each group (OLC and BLC) in pre- and post-testing. The OLC improved in all four components of $R L$ : defining research terms $(F(1,30)=$ 9.17, $p<0.01$, partial $\eta 2=0.23)$, identifying research problems $(F(1,30)=$ 12.27, $p<0.01$, partial $\eta 2=0.29)$, formulating research questions $(F(1,30)=$ 7.58, $p<0.01$, partial $\eta 2=0.202)$, and designing a research process $(F(1$, $30)=14.21, p<0.001$, partial $\eta 2=0.321)$.

The BLC also showed significant improvement on all of the repeated measures. Furthermore, students in the BLC outperformed students in the OLC in all components of $R L$ : defining research terms $(F(1,30)=45.76, p<$ 0.001 , partial $\eta 2=0.58)$, identifying research problems $(F(1,30)=58.78, p<$ 0.001 , partial $\eta 2=0.64)$, formulating research questions $(F(1,30)=49.17, p$ $<0.001$, partial $\eta 2=0.60)$, and designing a research process $(F(1,30)=$ 62.01, $\mathrm{p}<0.001$, partial $\eta 2=0.67)$.

To summarize, the immediate post-test effect didn't show significant differences in $R L$ between the two groups, but there was significant improvement in each skill separately with each LC reporting a sense of improvement immediately after the PBL intervention.

\subsection{Long-term effect of PBL on RL}


The second purpose of the study was to estimate the long-term effects of PBL in the different LCs. The dependent variable was the outcome of the Research Literacy Task which was completed one month after the intervention (the long-term effect). The independent variable was the LC (BLC or OLC). The One-way MANOVA test results indicate a significant overall difference between LCs for all four RL skills: $F(4,60)=7.06 p<.001$. Additionally, significant differences in defining and identifying skills emerged: $F(1,63)=14.60, \boldsymbol{p}<001$, and $F(1,63)=16.22, \boldsymbol{p}<001$, respectively. However, no significant differences were found in the formulation and designing skills: $F(1,63)=2.09, \boldsymbol{p}>05$, and $F(1,63)=1.56$, $\boldsymbol{p}>05$, respectively. Table 3 presents the means and standard deviations for the $R L T$.

In general, the findings indicate that pre-service teachers from the OLC significantly outperformed students in the BLC in most measures of RL skills. For example, evaluation of PBL processes in the OLCs reveal that social scaffolding was empowering for promotion of both design and formulation skills, while direct scaffolding was shown to be helpful only for formulation skills, as compared to the blended LC. Thus, a significant long-term effect was found in the OLC as compared to the blended LC with regard to identifying and defining a research problem.

\subsection{Social and direct scaffoldings in LCs during PBL}

The third purpose of the study was to investigate the processes of social and direct scaffolding in LC discussion forums with respect to the link between research literacy and pedagogy. In order to investigate the social scaffolding 
during PBL in the LCs, a one-way MANOVA was performed on the LC protocols for Defining, Identifying, Formulating, and Designing a research process related to students' pedagogical practice. The one-way MANOVA test results do not indicate a significant difference between the groups using direct scaffolding: $F(4,60)=2.07, p>.05$, but differences in social scaffolding did appear: $F(4,60)=3.7, p<.01$. A one-way ANOVA test was used to compare Direct Scaffolding (measured by the number of replies to each initiative) in the two groups. There was a significant difference between groups in formulating skills: $F(1,64)=5.41, p<.05$. The frequency of replies to each new formulation topic was significantly higher in the OLC than in the BLC. However, the results reveal no difference between the groups for direct scaffolding in defining skills $F(1,64)=0.73, p>.05$, identifying skills: $F(1,64)$ $=1.54, p>.05$, or designing skills: $F(1,64)=0.39, p>.05$.

The results of Social Scaffolding (which was measured by the number of responses and reactions by each forum participant) show significant differences between groups in formulating and designing skills: $F(1,64)=$ 3.88, $p<.05, F(1,64)=5.13, p<.05$, respectively. This means that the OLC participants show greater willingness to take part in reflective discussions about formulating and designing that had been initiated by their classmates than their counterparts in the BLC. However, there were no significant differences between the groups in the identifying and defining skills: $F(1,64)=$ 2.66, $p>.05 ; F(1,64)=1.14, p>.05$, respectively. Table 4 presents the means and the standard deviations for LCs (OLC, BLC) with respect to scaffolding. 
Our findings indicate that pre-service teachers from the OLC significantly outperform their counterparts in the BLC on most measures. This difference is most strongly manifested in PBL processes (both direct and social scaffolding) and in the long-term effect of PBL on RL. Table 5 contains a summary of the results.

\section{Discussion}

These outcomes shed new light on aspects of online PBL and on the four $R L$ skills. We first discuss possible reasons for differences in $\mathrm{RL}$ between the two groups in terms of immediate and long-term effects. Second, we extend our findings on the PBL process to direct and social scaffolding. And finally, we suggest new interpretations of the immediate and long-term effects of PBL in different LC environments.

\subsection{Immediate and long-term effects of PBL on RL}

The latest literature (Baturay \& Bay, 2010; Savery, 2015; Donnelly, 2010; Taheri, Sasaki, Chu \& Ngetha, 2016) defines PBL as a learner-centered instructional approach that empowers learners to conduct research, integrate theory and practice, and develop viable solutions to defined problems. The current study investigates the use of PBL in creating an up-to-date approach. Our results offer insight into the qualities of different LCs. While there was no significant difference in LCs with respect to immediate effects with both groups showing heightened awareness of $R L$ and higher self-assessment of their skill level, with respect to long-term effects, the OLC shows significantly greater assimilation of $\mathrm{RL}$ in two of the four skills: identifying and defining a research problem. Similar results with respect to attitudinal change were 
found by Hampden-Thompson \& Sundaram (2013) and Creamer, et al (2012). This research extends their findings by examining student achievement in addition to students' own perceptions of their learning and their attitudes.

Controversy in the literature remains about the immediate and long-term effects of PBL. For example, Strobel \& Barneveld (2009) claim that based on the nature of working memory, short-term retention is suitable for basic learning strategies (such as organizing and retrieving separate pieces of information). This is in contrast to long-term retention which is necessary for internalization and implementation of learning approaches and perceptions (such as the ability to identify and define a problem). In light of their findings concerning the advantages of $\mathrm{PBL}$ in long-term retention, the above mentioned researchers argue strongly for the overall superiority of PBL. The current study confirms their insights. This probably indicates that the intuitive "abilities" of RL (e.g., Identifying and Defining) acquired by participants in the OLC were assimilated into their long-term memories and therefore were reflected only in the long-term effect while advanced $R L$ skills (Formulation and Design) which were probably integrated into working memory were implemented immediately.

\subsection{PBL process during LCs}

The latest studies (Barber, et al., 2015; Franklin et al., 2015; Baturay \& Bay, 2010; Donnelly, 2010;Taheri, Sasaki, Chu \& Ngetha, 2016) report extensive use of different types of guidance within the PBL process. Bickhard (2013) claims that in order to navigate a reflective discussion aimed at conceptual changes, the moderator has to manage the LC by integrating direct self-scaffolding and 
social participant-based scaffolding (Creamer et al., 2012; Shea, Li \& Pickett, 2006).

Direct scaffolding refers to the moderator's or the participants' ability to create reflective discussions (Franklin et al., 2015) by encouraging cooperative enlightenment and deep internalization of knowledge and skills. Social-based scaffolding is described as constructivist collaborative guidance from classmates as indicated by their willingness to participate in reflective discussions (Creamer et al., 2012). Alongside the trend in the latest studies to compare the two types of scaffolding and their impact upon learning strategies, only a few recent studies have investigated the nature of the dynamics of online forums in different LC environments.

Our working assumption was that the ability of participants to create social interactions in LCs and to encourage classmates to participate in different learning discussions indicates a high level of $R L$ during the learning process (Creamer et al., 2012). We found expressions of significantly higher level scaffolding (both direct and social) for formulation skills in the online LC as opposed to the blended LC. The superiority of the online LCs was also found in social scaffolding for design skills. This can be interpreted in accordance with Donnelly (2010) who analyzes the contributions of blended and online learning forums using the PBL model and notes the importance of building a sense of community. He claims that LCs should be based upon appropriately coordinated communication tools that emphasize consistency of communication patterns. His analysis leads to the conclusion that community building depends on heightened levels of interaction and on harmonization of blended interaction channels. While this principle was maintained in the online 
LC of the current study, it was probably missing in the blended LC. Participants in the blended LC were alternately requested to create learning interactions in traditional and online formats. Probably the inconsistency of the communication channels and their differing patterns confused them, reducing the efficiency of the interpersonal interactions. This in turn led to significantly lower frequency and quality of both direct and social scaffolding as compared to the online LC.

\subsection{Practical implications, future research, and limitations}

The main purpose of this study was to compare an online Learning Community to a blended LC, focusing on students' ability to assimilate the link between Research Literacy and pedagogy. We had assumed that the pedagogic communication which took place in the blended environment would achieve significantly greater internalization of the knowledge and skills of $R L$ than that of the pure online environment (Willcoxson et al., 2011; Bettaz et al., 2016). This assumption was based on the claim that multichannel communication improves outcomes in declarative knowledge, cognitive flexibility and high-order skill acquisition (Park, 2011). However, our expectation was not only not confirmed, but we found that online-based pedagogic communication yields better results for most aspects of $R L$ and in the social interactivity in the virtual forums.

On the theoretical level, this study offers important insight into evaluating PBL communication with different kinds of scaffolding and social interaction in a $R L$ context. On the practical level, this study provides a perspective on an innovative method of assimilating the link between Research Literacy and 
pedagogy which has not been included in previous studies: Four basic RL skills which have practical as well as research applications were selected and undergraduate education students learned these skills in a virtual PBL environment. Based on our findings, we suggest that there be future studies to expand and explore this approach with different student populations. We propose that future research be conducted focusing on PBL methods and their influence upon the professional development of students and practitioners in the education field. Finally, we suggest increasing the theoretical knowledge in this area by conducting studies comparing immediate and long-term effects in different environments.

\section{References}

Barber, W., King, S., \& Buchanan, S. (2015). Problem Based Learning and Authentic Assessment in Digital Pedagogy: Embracing the Role of Collaborative Communities. Electronic Journal of e-Learning, 13(2).

Baturay, M. H., \& Bay, O. F. (2010). The effects of problem-based learning on the classroom community perceptions and achievement of web-based education students. Computers \& Education, 55(1), 43-52.

Bettaz, M., Al-Fuqaha, I., Mosteghanemi, M., Miloudi, M., Smar, O., \& Algeria, A. (2015). Transferring e-Learning Quality Management Practices into Faceto-Face Pedagogy. The International Journal of E-Learning and Educational Technologies in the Digital Media (IJEETDM), 1(1), 1-15.

Bickhard, M. H. (2013). Scaffolding and self-scaffolding: Central aspects of development. LT Winegar, Sc]. Valsiner (Eds), Chz'ldreri'sd U, 610, 33-52.

Chia, H. P., \& Pritchard, A. (2014). Using a virtual learning community (VLC) to facilitate a cross-national science research collaboration between secondary school students. Computers \& Education, 79, 1-15.

Creamer, E. G., Ghoston, M. R., Drape, T., Ruff, C., \& Mukuni, J. (2012). Using Popular Media and a Collaborative Approach to Teaching Grounded Theory Research Methods. International Journal of Teaching and Learning in Higher Education, 24(3), 415-420. 
Donnelly, R. (2010). Harmonizing technology with interaction in blended problem-based learning. Computers \& Education, 54(2), 350-359.

Earley, M. (2014) A synthesis of the literature on research methods education. Teaching in Higher Education, 19 (3), 242-253.

Franklin, B. M., Xiang, L., Collett, J. A., Rhoads, M. K. \& Osborn, J.L. (2015). Open problem-based instruction impacts understanding of physiological concepts differently in undergraduate students. Advances in Physiology Education, 39, 327-334

Hacohen. I., \& Ronen, M. (2011). The connection between quality of life at school and the students' social skills in different age groups and in different educational frameworks. Dapim, 52, 105-136.

Hampden-Thompson, G., \& Sundaram, V. (2013). Developing quantitative research skills and conceptualising an integrated approach to teaching research methods to education students. AISHE-J: The All Ireland in Higher Education, 5(3), 901-924.

Kilburn, D., Nind, M. \& Wiles, R. (2014) Learning as researchers and teachers: The development of a pedagogical culture for social science research methods? British Journal of Educational Studies, 62(2), 191-207.

Maor, D. (2003). The teacher's role in developing interaction and reflection in an online learning community. Educational Media International, 40(1-2), 127138.

Park, J. Y. (2011). Design education online: Learning delivery and evaluation. International Journal of Art \& Design Education, 30(2), 176-187.

Savery, J. R. (2015). Overview of problem-based learning: Definitions and distinctions. Essential Readings in Problem-Based Learning: Exploring and Extending the Legacy of Howard S. Barrows, 5-15.

Shank, G., \& Brown, L. (2013). Exploring educational research literacy. Wellington, J. (2015). Educational research: Routledge. (coding) Contemporary issues and practical approaches. Bloomsbury Publishing.

Shea, P., Li, C. S., \& Pickett, A. (2006). A study of teaching presence and student sense of learning community in fully online and web-enhanced college courses. The Internet and Higher Education, 9(3), 175-190.

Strobel, J. and Barneveld, A. (2009). When is PBL more effective? A metasynthesis of meta-analyses comparing PBL to conventional classrooms. Interdisciplinary Journal of Problem Based Learning 3(4), 2009.

Taheri, S. M., Sasaki, M., Chu, J. O., \& Ngetha, H. T. (2016). A Study of Teaching Problem Solving and Programming to Children by Introducing a 
New Programming Language. The International Journal of E-Learning and Educational Technologies in the Digital Media (IJEETDM), 2(1), 31-36.

Willcoxson, L., Manning, M. L., Johnston, N., \& Gething, K. (2011). Enhancing the Research-Teaching Nexus: Building Teaching-Based Research from Research-Based Teaching. International Journal of Teaching and Learning in Higher Education, 23(1), 1-10.

Wright, G. B. (2011). Student-Centered Learning in Higher Education. International Journal of Teaching and Learning in Higher Education, 23(1), 9297.

\section{Table 1:}

Means and SD of Demographic Parameters (Age, Study time), by groups

\begin{tabular}{ccc}
\hline & OLC & F2F BLC \\
$(N=31)$ & $(N=34)$ \\
\hline Age & & \\
M & 25 & 21.32 \\
SD & 7.66 & 1.63 \\
\hline Study time & & \\
M & .77 & .68 \\
SD & .44 & .47 \\
\hline
\end{tabular}

Table 2:

Means and SD of Research Literacy Inventory (RLI), by testing occasion (pre, post) and groups (OLC, BLC)

\begin{tabular}{ccccc}
\hline & \multicolumn{2}{c}{ OLC } & \multicolumn{2}{c}{ BLC } \\
& \multicolumn{2}{c}{$(N=31)$} & \multicolumn{2}{c}{$(N=34)$} \\
\hline Pre & Post & Pre & Post \\
\hline Recognize & & & & \\
M & 2.83 & 2.99 & 2.78 & 3.04 \\
SD & .52 & .45 & .54 & .49 \\
& & & & \\
\hline
\end{tabular}




\begin{tabular}{ccccc}
\hline Define & & & & \\
M & 2.77 & 2.97 & 2.83 & 3.09 \\
SD & .61 & .45 & .54 & .44 \\
& & & & \\
\hline Formulate & & & & \\
M & 2.72 & 2.87 & 2.68 & 2.91 \\
SD & .56 & .52 & .56 & .44 \\
& & & & \\
\hline Design & & & & 3.02 \\
M & 2.72 & 2.88 & 2.68 & .46 \\
SD & .68 & .44 & .54 & \\
& & & & \\
\hline
\end{tabular}

Table 3:

Means and SD of Research Literacy Task (RLT), by groups

\begin{tabular}{ccc}
\hline & OLC & F2F BLC \\
& $(N=31)$ & $(N=34)$ \\
Recognize & 2.29 & 2.0 \\
SD & .98 & .95 \\
\hline Define & 3.26 & \\
M & .85 & 2.29 \\
SD & & 1.14 \\
\hline Formulate & 2.77 & \\
M & 1.11 & 2.41 \\
SD & & 1.21 \\
\hline Design & 2.80 & 2.44 \\
M & .98 & 1.05 \\
SD &
\end{tabular}


Table 4:

Means and SD of Direct and Social scaffoldings during PBL, by groups

\begin{tabular}{|c|c|c|c|c|}
\hline & \multicolumn{2}{|c|}{$\begin{array}{c}\text { OLC } \\
(N=31)\end{array}$} & \multicolumn{2}{|c|}{$\begin{array}{c}\text { BLC } \\
(N=34)\end{array}$} \\
\hline & Direct & Social & Direct & Social \\
\hline \multicolumn{5}{|c|}{ Recognize } \\
\hline $\mathbf{M}$ & 1 & 0.64 & 0.72 & 0.24 \\
\hline SD & 1.6 & 1.05 & 0.87 & 0.54 \\
\hline \multicolumn{5}{|l|}{ Define } \\
\hline $\mathbf{M}$ & 1.03 & 0.23 & 0.76 & 0.43 \\
\hline SD & 1.09 & 0.56 & 1.13 & 0.81 \\
\hline \multicolumn{5}{|c|}{ Formulate } \\
\hline $\mathbf{M}$ & 0.6 & M & 0.6 & M \\
\hline SD & 1.07 & $\mathrm{SD}$ & 1.07 & $\mathrm{SD}$ \\
\hline \multicolumn{5}{|l|}{ Design } \\
\hline $\mathbf{M}$ & 0.2 & 0.16 & 0.05 & 0 \\
\hline SD & 1.09 & 0.37 & 0.22 & 0 \\
\hline
\end{tabular}

Table 5: Summary of Results.

Outcomes of the Variance Tests of PBL effects and PBL processes

\begin{tabular}{lcccc} 
& $\begin{array}{c}\text { Immediate } \\
\text { effect }\end{array}$ & $\begin{array}{l}\text { Long-term } \\
\text { effect }\end{array}$ & $\begin{array}{c}\text { Direct } \\
\text { scaffoldings }\end{array}$ & $\begin{array}{l}\text { Social } \\
\text { scaffoldings }\end{array}$ \\
\hline Recognize & 1.19 & $16.22^{* * *}$ & 1.41 & 2.85 \\
\hline
\end{tabular}




\begin{tabular}{|c|c|c|c|c|}
\hline Define & 0.15 & $14.6^{\star \star \star}$ & 0.74 & 0.91 \\
\hline Formulate & 0.17 & 1.57 & $8.25^{\star \star}$ & $6.62^{*}$ \\
\hline Design & 1.64 & 2.09 & 0.54 & $6.34^{*}$ \\
\hline
\end{tabular}

\author{
Appendix 1 \\ Adapted Research Literacy Inventory (Shank \& Brown, 2013) \\ Sample pre-test and post-test items
}

1. I know what the research problem is.

2. I know how to identify a researchable problem in the school, the classroom, or the kindergarten.

3. I know how to define a research problem.

4. I know what the research question is.

5. I know how to formulate a research question.

6. I know what a research procedure is.

7. I know how to design a research investigation.

8. I know how to identify procedures for quantitative and qualitative research.

9. I know what a research tool is.

10. I know how to formulate appropriate research tools.

11. I know how to distinguish between quantitative and qualitative research tools.

12. I know how to recognize an academic article.

13. I know how to read and understand an academic article.

14. I know how to analyze the structure of an academic article (Introduction, research question, research procedure, summary).

15. I know how to summarize an academic article.

16. I know how to answer questions based on an academic article.

17. I know how to write an article in academic style, using sources to support my arguments.

18. I know how to judge whether an academic article is relevant for me.

\title{
Figure 1
}

Summary of the Research Intervention, Measures and the Issues Examined

\begin{tabular}{|l|lll|}
\hline Lessons & \multicolumn{1}{l}{$\begin{array}{l}\text { The theme of a } \\
\text { LCs' discussion }\end{array}$} & The measures & $\begin{array}{l}\text { The issue } \\
\text { examined }\end{array}$ \\
\hline Week 1 & - & RLI (pre-test) & Awareness of RL \\
\hline Week 2 & Recognizing & LCs' protocol & Social and Direct \\
\hline
\end{tabular}




\begin{tabular}{|c|c|c|c|}
\hline & research problem & & $\begin{array}{l}\text { scaffoldings, via the } \\
\text { PBL process }\end{array}$ \\
\hline Week 5 & $\begin{array}{l}\text { Defining research } \\
\text { terms }\end{array}$ & LCs' protocol & \\
\hline Week 8 & $\begin{array}{l}\text { Formulating } \\
\text { research question }\end{array}$ & LCs' protocol & \\
\hline Week 11 & $\begin{array}{l}\text { Designing research } \\
\text { process }\end{array}$ & LCs' protocol & \\
\hline Week 12 & - & RLI (post-test) & $\begin{array}{l}\text { Awareness of RL, } \\
\text { the immediate effect } \\
\text { of PBL }\end{array}$ \\
\hline Week 16 & - & RL Task & $\begin{array}{l}\text { Actual ability to } \\
\text { link between RL } \\
\text { and pedagogy, the } \\
\text { delayed effect of } \\
\text { PBL }\end{array}$ \\
\hline
\end{tabular}

Figure 2. A Scoring Scheme of the Research Literacy Task (RLT)

\section{for 4 Research Literacy Skills}

\begin{tabular}{|c|c|c|c|c|}
\hline Score & $\begin{array}{c}4 \\
\text { Answer } \\
\text { contains } \\
\text { conceptual and } \\
\text { procedural } \\
\text { elements }\end{array}$ & $\begin{array}{c}3 \\
\text { Conceptual } \\
\text { answer }\end{array}$ & $\begin{array}{c}2 \\
\text { Procedural } \\
\text { answer }\end{array}$ & $\begin{array}{c}1 \\
\text { Partial answer }\end{array}$ \\
\hline Description & $\begin{array}{l}\text { The participant } \\
\text { knows the } \\
\text { theoretical and } \\
\text { practical influences } \\
\text { of this issue }\end{array}$ & $\begin{array}{l}\text { The participant } \\
\text { knows the } \\
\text { theoretical } \\
\text { influences of this } \\
\text { issue }\end{array}$ & $\begin{array}{l}\text { The participant } \\
\text { knows how to deal } \\
\text { with this issue }\end{array}$ & $\begin{array}{c}\text { The participant's } \\
\text { knowledge of this } \\
\text { issue is partial }\end{array}$ \\
\hline Recognizing & $\begin{array}{l}\text { This problem is } \\
\text { familiar to me } \\
\text { because as a } \\
\text { beginning teacher I } \\
\text { am in a situation in } \\
\text { which the types of } \\
\text { conversation I create } \\
\text { in my lessons impacts }\end{array}$ & $\begin{array}{l}\text { This issue has become } \\
\text { familiar to me since I } \\
\text { transferred from early } \\
\text { childhood education } \\
\text { to community } \\
\text { education in which } \\
\text { there is a strong }\end{array}$ & $\begin{array}{l}\text { It is possible to } \\
\text { recognize that values } \\
\text { such as listening, } \\
\text { dialogue, and } \\
\text { respectful } \\
\text { interpersonal relations } \\
\text { cause a reduction in } \\
\text { violence. }\end{array}$ & $\begin{array}{l}\text { It is possible to } \\
\text { identify this } \\
\text { phenomenon in } \\
\text { many places. }\end{array}$ \\
\hline
\end{tabular}




\begin{tabular}{|c|c|c|c|c|}
\hline & $\begin{array}{l}\text { the both the social } \\
\text { quality and the level } \\
\text { of empathy in the } \\
\text { interactions among } \\
\text { the pupils }\end{array}$ & $\begin{array}{l}\text { emphasis on the } \\
\text { quality of life in the } \\
\text { school. }\end{array}$ & & \\
\hline Defining & $\begin{array}{l}\text { The difficulty in the } \\
\text { research stems from the } \\
\text { lack of awareness on the } \\
\text { part of school staff, } \\
\text { particularly home room } \\
\text { teachers, regarding the } \\
\text { strength of the } \\
\text { connection between } \\
\text { school climate and } \\
\text { interactions between } \\
\text { pupils. Examining the } \\
\text { school climate variables } \\
\text { and the relationship } \\
\text { between them and } \\
\text { social skills helps to } \\
\text { explain the influence of } \\
\text { school climate on the } \\
\text { pupils' social } \\
\text { competence. }\end{array}$ & $\begin{array}{l}\text { Currently., many } \\
\text { researchers see } \\
\text { classroom climate as } \\
\text { a factor which } \\
\text { influences social } \\
\text { processes and a } \\
\text { sense of belonging. }\end{array}$ & $\begin{array}{l}\text { Teachers do not } \\
\text { associate the school } \\
\text { quality of life with } \\
\text { social skills. }\end{array}$ & $\begin{array}{l}\text { Teachers aren't } \\
\text { aware of this } \\
\text { problem. }\end{array}$ \\
\hline Formulating & $\begin{array}{l}\text { An appropriate } \\
\text { research question for } \\
\text { this study should refer } \\
\text { to the relationship } \\
\text { between school } \\
\text { climate and students' } \\
\text { social skills. For } \\
\text { example, what is the } \\
\text { impact of school } \\
\text { climate on each of the } \\
\text { social skills of the } \\
\text { learners. }\end{array}$ & $\begin{array}{l}\text { What is the quality of } \\
\text { the relationship } \\
\text { between school } \\
\text { climate and the social } \\
\text { skills of the students in } \\
\text { different streams of } \\
\text { education? }\end{array}$ & $\begin{array}{l}\text { Is there a link } \\
\text { between the quality } \\
\text { of school life and } \\
\text { students' social } \\
\text { skills? }\end{array}$ & $\begin{array}{l}\text { What is the quality } \\
\text { of the school } \\
\text { climate? }\end{array}$ \\
\hline Design & $\begin{array}{l}\text { The added value of } \\
\text { my proposed } \\
\text { research process is } \\
\text { the ability to test the } \\
\text { quality of school life } \\
\text { and its relationship to } \\
\text { multiple indices of } \\
\text { social skills... }\end{array}$ & $\begin{array}{l}\text { The added value of } \\
\text { my proposed research } \\
\text { process is to identify } \\
\text { the unique contribution } \\
\text { of quality of life to } \\
\text { these measures each } \\
\text { of them separately } \\
\text { and all together }\end{array}$ & $\begin{array}{l}\text { The research tool I } \\
\text { have proposed is } \\
\text { designed to examine } \\
\text { the relationship } \\
\text { between school } \\
\text { quality of life and the } \\
\text { students' social skills }\end{array}$ & $\begin{array}{l}\text { I have proposed a } \\
\text { research process } \\
\text { which is based on } \\
\text { observations. }\end{array}$ \\
\hline
\end{tabular}

